\title{
ANÁLISE HIDROGEGQUÍMICA PRELIMINAR DAS FONTES DOS ARREDORES DA BACIA DE SÃO PAULO
}

\author{
MÁRIA SZIKSZAY* e JEAN-MARIE TEISSEDRE**
}

\begin{abstract}
The objective of our work is to present the results of an hydrogeochemical study of springs around the São Paulo Tertiary Basin. In that region they emerge from diaclases, fissures and joints in different types of crystalline rocks.

All the analyzed waters have similar physico-chemical characteristics: temperature close to the annual medium temperature of the air; low conductivity; total salinity under $100 \mathrm{mg} / \mathrm{l}$; acid $\mathrm{pH}$ 4.7-5.5; radioactivity $0.7-20.7 \mathrm{nCi} / \mathrm{l}$.

Among the major elements the earth-alcalines are predominant, and the trace elements show variable concentrations. The waters can be classified as magnesian-bicarbonated. On the diagram of Piper, different groups could be separated reflecting the rocks in which the waters circulate.

The study of different characteristical relations indicates the relationships between the chemical composition of the waters and the surface lithology, as well as the probable origin of the waters.
\end{abstract}

INTRODUC̣Ão A região de ocorrência das fontes estudadas é abrangida por uma circunferência de cerca de $50 \mathrm{~km}$ de raio, em torno da cidade de São Paulo. A área apresenta um relevo de colinas suaves e recebe uma pluviometria média anual de $1311 \mathrm{~mm}$. Todas as emergências estão situadas entre as altitudes de 750 e $800 \mathrm{~m}$.

Os trabalhos anteriores enfocaram, fundamentalmente, os aspectos terapêuticos, dentre os quais destaca-se o de Souza Lopes (1956), ou preocuparam-se com medidas da radioatividade, Longo (1967).

As pesquisas ora desenvolvidas visam estabelecer a classificação química das águas das fontes e as suas correlações com as litologias dos locais de emergência. Nesse trabalho apresentamos os resultados referentes às fontes situadas nos arredores da região metropolitana da Grande São Paulo, tendo em vista o seu interesse sócio-econômico. Os estudos em andamento visam determinar as características geoquímicas das fontes do Estado de São Paulo.

Agradecemos ao Instituto de Geociências pelo apoio logístico e à Fundação de Amparo à Pesquisa do Estado de São Paulo (FAPESP) pela ajuda financeira. Agradecemos, também, a gentileza dos responsáveis ou administradores das empresas de exploração das fontes.

Metodologia A metodologia dos trabalhos compreendeu: a) a caracterização do contexto geológico das zonas de emergência; b) a coleta de amostras de água para análise físico-química no campo e no laboratório; c) a elaboração de um mapa de localização das fontes; e d) a interpretação dos resultados.

A localização das fontes foi efetuada por meio de informações bibliográficas, dos rótulos de água engarrafada encontrada no comércio e por meio de informações verbais, obtidas junto aos habitantes dos arredores.

TRABALHO DE CAMPO No campo foram realizados os seguintes estudos: levantamento geológico dos arredores de cada surgência, identificação petrográfica das rochas

\footnotetext{
*Instituto de Geociências, Departamento de Geologia Geral da Universidade de São Paulo

**Instituto de Pesquisas Tecnológicas, Div. de Minas e Geologia Aplicada, São Paulo
} 
e análises físico-químicas das águas. Foram feitas as seguintes determinações: a temperatura da água e do ar, o $\mathrm{pH}$, a condutividade, o oxigênio $\left(\mathrm{O}_{2}\right)$, o gás carbônico $\left(\mathrm{CO}_{2}\right)$, o bicarbonato $\left(\mathrm{HCO}_{3}^{-}\right)$, o cloreto $\left(\mathrm{Cl}^{-}\right)$, o sulfato $\left(\mathrm{SO}_{4}^{-}\right)$, o fosfato $\left(\mathrm{PO}_{4}^{-}{ }^{-}\right)$, a amônia $\left(\mathrm{NH}_{4}^{+}\right)$, o nitrito $\left(\mathrm{NO}_{2}^{-}\right)$, o nitrato $\left(\mathrm{NO}_{3}^{-}\right)$, o fluoreto $\left(\mathrm{F}^{-}\right)$, o iodeto $\left(\mathrm{I}^{-}\right)$, o brometo $\left(\mathrm{Br}^{-}\right)$, o cálcio $\left(\mathrm{Ca}^{++}\right)$, o magnésio $\left(\mathrm{Mg}^{++}\right)$, o ferro total $\left(\mathrm{Fe}^{2+}+\mathrm{Fe}^{3+}\right)$, o alumínio $\left(\mathrm{Al}^{3+}\right)$ e a sílica $\left(\mathrm{SiO}_{2}\right)$.

Os métodos utilizados foram titulométricos ou espectrofotométricos com o aparelho portátil "HACH Water Analysis Kit".

TRABALHO DE LABORATORIO Os seguintes elementos e compostos foram analisados no laboratório: o sódio $\left(\mathrm{Na}^{+}\right)$, o potássio $\left(\mathrm{K}^{+}\right)$, o boro $\left(\mathrm{B}^{3+}\right)$, o cobre $\left(\mathrm{Cu}^{++}\right)$, o crômio total $\left(\mathrm{Cr}^{3+}+\mathrm{Cr}^{6+}\right)$, o níquel $\left(\mathrm{Ni}^{3+}\right)$, o chumbo $\left(\mathrm{Pb}^{++}\right)$, o zinco $\left(\mathrm{Zn}^{++}\right)$e detergentes aniônicos. As análises foram efetuadas com o aparelho mencionado antes, salvo o sódio e o potássio, que foram analisados com fotômetro de chama. Foi feito o balanço iônico e somente foram utilizadas análises com erro inferior a $\pm 10 \%$

Para melhor visualização da relação entre composição química das águas das fontes e litologia, estas foram plotadas no mapa geológico (Fig. 1): Jandira - a noroeste de São Paulo, no município de Jandira; Pluma - Fonte dos Bandeirantes - a oeste de São Paulo, situada no km 21 da Via Raposo Tavares, no município de Cotia; Embu - Fonte dos Jesuítas - a sudoeste de São Paulo, na BR2, no município de Embu; Pilar - Fonte da Encosta N. 1, Fonte da Montanha e Serrania - a sudeste de São Paulo, na Estância Pilar, no município de Ribeirão Pires; Petra - Fonte Dotta - a sudeste de São Paulo, no município de Rio Grande da Serra; Poá - Fontes Áurea e Primavera - a nordeste de São Paulo, no município de Poá; Rochágua - Fonte Jaraguá - a noroeste de São Paulo, na Fazenda Santo Antônio, município de Perus, estrada velha de Campinas; Fontális Fonte São João - a norte de São Paulo, no bairro do Tremembé, e Petrópolis - na bacia sedimentar de São Paulo, no bairro do Brooklin.

Quadro geológico das fontes Nos arredores da bacia de São Paulo encontram-se rochas pertencentes ao Grupo São Roque, ao Complexo Gristalino e à Faixa Gnáissica Intermediária, Coutinho (1972). A litologia mais freqüente é representada, essencialmente, por gnaisses, migmatitos, micaxistos e granitos pré-cambrianos.

Em geral, as fontes emergem das fissuras, fraturas e diaclasamentos dessas rochas ou nos contatos entre dois tipos de rocha, e localizam-se, predominantemente, nos vales ou baixadas.

As feições geológicas locais ou dos arredores e as condições de emergência de cada fonte são expostas a seguir.

Jandira - A geologia é representada por granito e a água surge através de diáclases localizadas no fundo de uma baixada.

Pluma - Fonte dos Bandeirantes - A fonte encontra-se no contato entre dois tipos de granitos: um granito pórfiro com fenocristais de feldspato e um granito com textura mais aplítica. O granito pórfiro constitui o muro que domina a fonte, formando um maciço homogêneo pouco alterado. O granito aplítico apresenta-se em forma de veio com uma direção $\mathrm{N} 40^{\circ} \mathrm{E}$. A água surge no contato entre as duas rochas, através das fraturas e diáclases abertas.

$E m b u$ - Fonte dos Jesuítas - Como foi possível observar no fundo da captação, a água surge de uma rocha cinzenta, equigranular e diaclasada segundo a lineação. Essa rocha, conhecida como gnaisse de Embu, aflora exclusivamente a montante da fonte e possui uma lineação de direção nordeste, favorecendo fraturas e diáclases nessa mesma 
MAPA GEOLÓGICO DE SÃO PAULO Fonte: C.P.R.M. - 1974

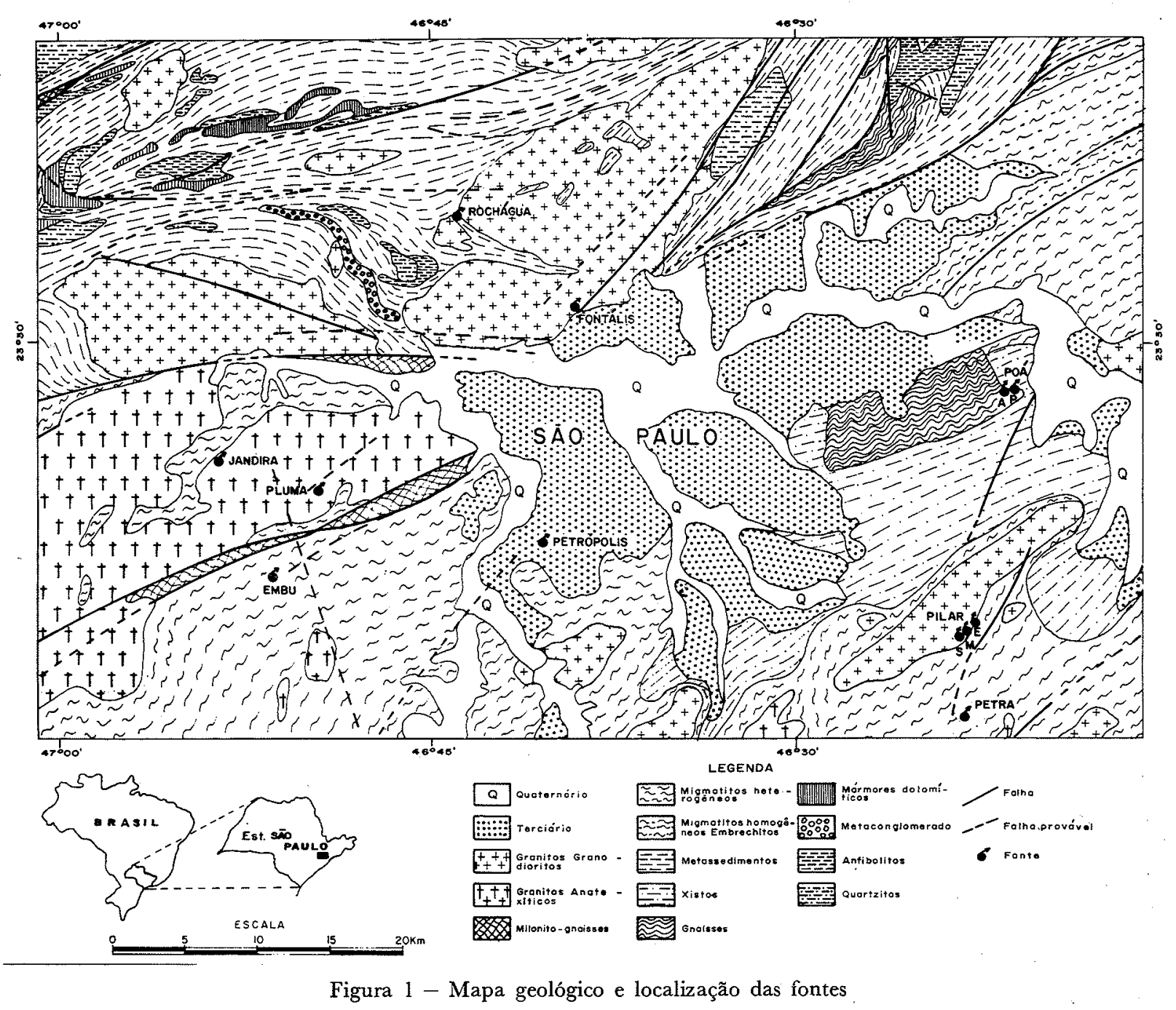


direção. Aparentemente, a julgar pela presença de um muro de afloramento, pode-se identificar uma pequena falha a nordeste sobre a qual se situaria a fonte. As lineações encontradas nessas rochas e no paredão justificariam essa hipótese, além de evitar as infiltrações das águas do riacho que corre perpendicularmente. Essas rochas, mencionadas como gnaisses na literatura, são mais representativas de um granito sintectônico, embora sua textura lhe dê aparência de um migmatito. Segundo os estudos realizados por Coutinho (1972) a composição mineralógica desses gnaisses é a de um adamellito com uma paragênese a quartzo, microclínio, plagioclásio, biotita, muscovita e minerais acessórios, tais como, titanita, apatita, calcita e allanita.

Pilar - Fonte da Encosta N..$^{\circ}$, Fonte da Montanha e Serrania - O levantamento mostrou que a Fonte da Encosta N. ${ }^{\circ} 1$ se situa num contato gradativo entre gnaisses e biotita-granito muito orientado. Esse contato, de direção praticamente este-oeste, é pouco visível da estrada em frente à estância. Infelizmente, não foi possível examinar a rocha no fundo da captação, que é muito profunda, além de estar localizada no fundo do vale, ao pé da encosta. Em compensação, nas fontes da Montanha e Serrania a rocha é bem visível e foi identificada como granito sintectônico. Nos afloramentos observados, nota-se a presença de veios de pegmatito com quartzo, feldspato, muscovita e turmalina, principalmente perto da Fonte Serrania; as orientações são bem evidenciadas nessas rochas pela lâminas de biotita, na proximidade do contato, e tendem a se tornar nebulosas à medida que se afastam. De um modo geral, a água sai das diáclases e fissuras abertas nas lineações da rocha armazenadora.

Petra - Fonte Dotta - Essa fonte foi obtida a partir das escavações realizadas nos gnaisses para explorar a grafita. $\mathrm{Na}$ realidade é uma fonte de fratura, produzida segundo a xistosidade de direção nordeste e mergulho de $70^{\circ} \mathrm{E}$. Nesses gnaisses foram encontrados nódulos de grafita. A Fonte Dotta localiza-se ao sul das de Pilar. Os gnaisses são a continuação de uma parte daqueles mapeados na Fonte da Encosta N. ${ }^{\circ} 1$ e a sua paragênese é a mesma.

Poá - Fonte Aurea e Fonte Primavera - A rocha é somente visível no fundo da captação da Fonte Áurea e identificada como gnaisse de direção noroeste, evidenciada pela lamela de biotita. A água emerge a partir das fissuras e diáclases abertas segundo a xistosidade. Somente na nascente foi possível observar esses gnaisses, devido à inexistência de afloramento nos arredores imediatos ou afastados. Na Fonte Primavera situada aproximadamente à $1 \mathrm{~km}$ da Fonte Aurea, aparece uma variação de fácies na litologia encontrada à montante da fonte. A rocha muito alterada apresenta-se como uma sucessão de camadas pretas, com grande quantidade de biotita, e de camadas brancas, cujos minerais têm o aspecto de talco. Essa rocha parece ser um micaxisto ou um sericita-clorita xisto com orientação noroeste. Além disso, encontram-se, também, nas proximidades da surgência, blocos de quartzito e megacristais de muscovita no solo de alteração.

Rochágua - Fonte Jaraguá - A fonte está situada no contato entre os xistos e outras rochas, em filões, tais como pegmatitos com turmalina e rochas calcossilicatadas (homfels) com anfibólio, quartzo e feldspato, diopsídio e epídoto. Esse último tipo de rocha pode ser denominada também de hornblenda xisto ou de anfibolito. No caso estudado elas ocorrem dentro dos xistos, na faixa de transição com o corpo granítico. Nos pegmatitos com turmalina, foi anotada, também, a presença de granada e de apatita. Os xistos possuem em uma direção noroeste e mergulhos de $75^{\circ} \mathrm{NE}$ à subvertical, favorecendo, portanto, a emergência da água no sentido da xistosidade. 
Fontális - Fonte São João - A surgência é dominada pelo muro de granito pertencente ao conjunto granítico da Cantareira. Esse granito, com textura equigranular, localiza-se a sudeste do grande corpo granítico porfiroblástico. Apresenta uma composição mineralógica com quartzo, feldspato potássico e plagioclásio, biotita, dando-lhe uma aparência mesocrática e o aspecto de um granodiorito. A jusante da fonte, esse maciço é cortado por um veio de rochas verdes, aparentemente horffels ou anfibolitos, que se situam ao longo de uma falha, visível na pedreira situada atrás da fonte, de direção $\mathrm{N} 60^{\circ} \mathrm{W}$. O tipo de surgência é devido a diáclases dentro do granito.

Petrópolis - A captação da água é feita por intermédio de um poço profundo de $4^{\prime \prime}$ de diâmetro. O poço perfurado, até aproximadamente $140 \mathrm{~m}$ de profundidade, capta as águas das formações terciárias da bacia de São Paulo. Uma descrição geológica de uma outra perfuração realizada à $80 \mathrm{~m}$ de distância da primeira, evidencia uma sucessão de camadas argilosas e arenosas, até atingir o substrato granítico ou gnáissico. Tab. I.

A geologia das diferentes fontes e as condições de emergência estão sintetizadas na

Características físicas das águas As características físicas das águas das fontes estão apresentadas na Tab. II.

Os valores de temperatura, $\mathrm{pH}$ e condutividade foram medidos no local, na própria fonte ou imediatamente na saída da captação. Os valores de radioatividade foram coligidos de Longo (1967). As vazões foram geralmente estimadas a partir dos volumes explorados.

TEMPERATURA Os valores obtidos variam de 18,5 a $20^{\circ} \mathrm{C}$. Essas temperaturas correspondem, praticamente, às temperaturas médias do ar da região. $O$ caso da Fonte Petrópolis, cuja temperatura é ligeiramente superior $\left(22 ; 5^{\circ} \mathrm{C}\right)$, seria devido à influência do gradiente geotérmico, se considerarmos a profundidade do poço. Segundo Castany

Tabela I - Tipo de rocha e forma de surgência

\begin{tabular}{lll}
\hline \multicolumn{1}{c}{ Fonte } & \multicolumn{1}{c}{ Tipo de surgência } & \multicolumn{1}{c}{ Rocha } \\
\hline Jandira & fissuras e diáclases & granito \\
\hline Pluma - Fonte dos Bandeirantes & contato entre dois granitos & granito \\
\hline Embu - Fonte dos Jesuítas & fissura e falha & gnaisse migmatito \\
\hline Pilar - Fonte da Encosta N. ${ }^{\circ} 1$ & contato gnaisse-granito & gnaisse granito \\
\hline Pilar - Fonte da Montanha & fissura e diáclases & granito \\
\hline Pilar - Fonte Serrania & fissura e diáclases & granito sintectônico \\
\hline Petra - Fonte Dotta & fissura - xistosidade & gnaisse \\
\hline Poá - Fonte Aurea & fissura e diáclases - xistosidade & gnaisse \\
\hline Poá - Fonte Primavera & xistosidade e fissuras & micaxistos ou xistos \\
\hline Rochágua - Fonte Jaraguá & contato xisto - hornfels & hornfels e xistos \\
\hline Fontális - Fonte São João & fissura e diáclases & granodiorito \\
\hline Petrópolis & poço & sedimentos terciários \\
\hline
\end{tabular}


Tabela II - Resultados das medidas físicas

\begin{tabular}{|c|c|c|c|c|c|c|}
\hline Fonte & $\begin{array}{l}\text { Data de } \\
\text { análise }\end{array}$ & $\begin{array}{c}\mathrm{T} \\
\mathrm{em}\end{array}{ }^{\circ} \mathrm{C}$ & $\mathrm{pH}$ & $\begin{array}{c}\text { Condutividade } \\
\mu \mathrm{\delta} / \mathrm{cm}\end{array}$ & $\begin{array}{c}\text { Radioatividade } \\
\mathrm{nCi} / 1^{* *}\end{array}$ & $\begin{array}{c}\text { Vazão } \\
1 / \mathrm{s}\end{array}$ \\
\hline Jandira & $13 / 01 / 76$ & 20 & 5,3 & 38 & 0,7 & \\
\hline $\begin{array}{l}\text { Pluma - Fonte dos } \\
\text { Bandeirantes }\end{array}$ & $7 / 11 / 75$ & 19 & 5,3 & 47 & 8,0 & 0,47 \\
\hline $\begin{array}{l}\text { Embu - Fonte dos } \\
\text { Jesuítas }\end{array}$ & $4 / 07 / 75$ & 19 & 4,7 & 45 & 3,6 & 0,15 \\
\hline $\begin{array}{c}\text { Pilar - Fonte da } \\
\text { Encosta N. }{ }^{\circ} 1\end{array}$ & $26 / 09 / 75$ & 19 & 5,3 & 32 & 3,7 & $0,14^{*}$ \\
\hline $\begin{array}{l}\text { Pilar - Fonte da } \\
\text { Montanha }\end{array}$ & $26 / 09 / 75$ & 19 & 5,3 & 28 & 4,1 & $0,12^{*}$ \\
\hline $\begin{array}{l}\text { Pilar - Fonte } \\
\text { Serrania }\end{array}$ & $26 / 09 / 75$ & 18,5 & 5,3 & 35 & 3,3 & $0,06^{*}$ \\
\hline $\begin{array}{l}\text { Petra - Fonte } \\
\text { Dotta }\end{array}$ & $10 / 10 / 75$ & 18,5 & 5,0 & 28 & 3,9 & $0,23^{*}$ \\
\hline $\begin{array}{l}\text { Poá - Fonte } \\
\quad \text { Aurea }\end{array}$ & $10 / 07 / 75$ & 20 & 5,0 & 30 & 15,3 & $0,19^{*}$ \\
\hline $\begin{array}{c}\text { Poá - Fonte } \\
\text { Primavera }\end{array}$ & $10 / 07 / 75$ & 19 & 5,0 & 24 & & 0,10 \\
\hline $\begin{array}{l}\text { Rochágua - Fonte } \\
\text { Jaraguá }\end{array}$ & $24 / 10 / 75$ & 20 & 5,5 & 107 & 20,9 & $0,37^{*}$ \\
\hline $\begin{array}{l}\text { Fontális - Fonte } \\
\text { São João }\end{array}$ & $19 / 11 / 75$ & 19 & 5,3 & 58 & 4,8 & 0,05 \\
\hline Petrópolis & $19 / 11 / 75$ & 22,5 & 5,3 & 95 & & $16,6^{*}$ \\
\hline
\end{tabular}

*Vazão estimada segundo volumes explorados

**Segundo Longo (1967)

(1967), águas com temperaturas inferiores ou iguais a $20^{\circ} \mathrm{C}$ podem ser consideradas como fontes frias.

pH O pH varia de 4,7 a 5,5 e bem caracteriza águas provenientes de granitos, rochas metamórficas e arenitos silicosos da bacia sedimentar.

CONDUTIVIDADE Os valores variam entre 24 e $107 \mu \% / \mathrm{cm}$. A condutividade é, portanto, geralmente baixa, indicando uma mineralização fraca, representativa de rochas cristalinas, mesmo considerando-se o forte intemperismo da região. Observa-se que a condutividade média é próxima de $35 \mu \widetilde{\mathrm{S}} \mathrm{cm}$ para a grande maioria, excetuando-se as águas das Fontes Rochágua e Petrópolis.

RADIOATIVIDADE Os valores da radioatividade temporária variam de 0,7 a 20,9 nCi/l. As águas das Fontes Jandira, Embu, Pilar (F. Serrania) são consideradas como fracamente radioativas e as outras são radioativas na fonte de emergência, segundo o Código 
de Minas do Brasil. Somente as águas da Fonte Rochágua pertencem à classe de águas fortemente radioativas. Essa radioatividade pode ser devida à presença de minerais acessórios (apatita) identificados nas rochas, em filões e aos depósitos de uranita existente nas fratura das rochas.

VAZÃO Na grande maioria, as vazões foram estimadas a partir dos volumes explorados ou segundo dados de testes anteriores à exploração. Em geral, não ultrapassam $0,5 \mathrm{l} / \mathrm{s}$. São, portanto, fontes de pequena vazão natural, salvo a de Petrópolis onde a água é bombeada. A variação anual da vazão não é conhecida mas, supốe-se que, face à pluviometria abundante e constante, ela deva ser fraca.

Características químicas das águas Nas Tabs. III e IV apresentamos os resultados das determinações realizadas. A análise desses dados revela que a concentração total de sais é baixa em todas as águas. A concentração de oxigênio não mostra grande variação (12-28 $\mathrm{mg} / \mathrm{l})$, indicando águas superficiais, em contato com o ar ou pouco profundas.

As determinações de gás carbônico na fonte revelaram teores variando de $28-88 \mathrm{mg} / \mathrm{l}$. A origem do $\mathrm{CO}_{2}$ pode ser diversa; no caso estudado admitimos origem não-endógena, tendo como fonte principal reações químicas e bioquímicas. $\mathrm{O}$ valor mais baixo verifica-se na água da Fonte Petrópolis onde, devido à profundidade do poço $(140 \mathrm{~m})$, as reações bioquímicas são menos freqüentes. Os dois valores mais elevados ocorrem nas Fontes Poá (F. Primavera) e Fontális, ambas bem próximas da superfície e numa região com vegetação abundante.

Os teores em bicarbonato variam de $10-50 \mathrm{mg} / \mathrm{l}$, em média $20 \mathrm{mg} / \mathrm{l}$, e são os ânions predominantes nas águas das fontes estudadas. Águas bicarbonatadas caracterizam águas superficiais ou de pouca profundidade.

Tabela III - Resultados das análises - Elementos maiores (mg/l). Analisadas por M. Szikszay

\begin{tabular}{|c|c|c|c|c|c|c|c|c|c|c|c|c|c|c|c|c|c|c|}
\hline Nome da Fonte & $\begin{array}{c}\text { Data da } \\
\text { análise }\end{array}$ & $\begin{array}{l}\text { Sais totais } \\
\text { dissolvidos }\end{array}$ & $\mathrm{O}_{2}$ & $\mathrm{CO}_{2}$ & $\mathrm{Ca}$ & $\mathrm{Mg}$ & $\mathrm{Na}$ & $\mathrm{K}$ & Al & $\mathrm{Fe}$ & $\mathrm{SiO}_{2}$ & $\mathrm{HCO}_{3}$ & $\mathrm{Cl}$ & $\mathrm{SO}_{4}$ & $\mathrm{PO}_{4}$ & $\mathrm{NH}_{4}$ & $\mathrm{NO}_{2}$ & $\mathrm{NO}_{3}$ \\
\hline Jandira & $13 / 01 / 76$ & 39 & 12 & 40 & 3,5 & 2,5 & 1,5 & 2,1 & 0,01 & 0,04 & 3,6 & 20 & 2,0 & 2,0 & 0,05 & 0,05 & 0,05 & 1,9 \\
\hline $\begin{array}{l}\text { Plumia - F, dos } \\
\text { Bandeirantes }\end{array}$ & $7 / 11 / 75$ & 42 & 16 & 48 & 1,9 & 2,3 & 3,3 & 1,5 & 0,01 & $.0,03$ & 3,7 & 20 & 2,0 & 1,0 & 0,18 & 0,3 & 0,1 & 6,0 \\
\hline $\begin{array}{l}\text { Embü-F. dos } \\
\text { Yesuítas }\end{array}$ & $4 / 07 / 75$ & .45 & 13 & 52 & 4,4 & 2,2 & 3,2 & 1,6 & 0,01 & 0,04 & 1,1 & 18 & 1,0 & 0 & 0,15 & $\mathbf{0}$ & 0,09 & 10,3 \\
\hline $\begin{array}{l}\text { Pilar - F. da } \\
\text { Encosta N. } ._{1}^{\circ}\end{array}$ & $26 / 09 / 75$ & 34 & 19 & 44 & 1,9 & 2,5 & 1,1 & 2,7 & 0 & 1,1 & 3,6 & $\because 12$ & 3,5 & 3,0 & 0 & 0 & 0,08 & 3,2 \\
\hline $\begin{array}{l}\text { Pilar - F. da } \\
\text { Montanha }\end{array}$ & $26 / 09 / 75$ & 32 & 17 & 48 & 1,8 & 2,6 & 3,2 & 1,1 & 0,018 . & 0 & 3,7 . & 18 & 1,5 & 0 & 0,06 & o & 0,2 & 4,2 \\
\hline $\begin{array}{l}\text { Pilar - F. } \\
\text { Serrania }\end{array}$ & $26 / 09 / 75$ & 38 . & 17 & 32 & 1,2 & 3,5 & 2,1 & 0,6 & 0,018 & 0,05 & 3,0 & 18 & 2,0 & 1,0 & 0,1 & $\mathbf{0}$ & 0,06 & 3,6 \\
\hline Petra - F. Dotta & $10 / 10 / 75$ & 30 & 28 & 36 & 0,5 & 3,5 & 1,6 & 1,0 & 0,001 & 0,05 & 2,5 & 10 & 3,0 & 2,0 & 0,07 & 0,5 & 0,03 & 6,3 \\
\hline Poá - F. Áurèa & $10 / 07 / 75$ & 32 & 13 & 60 & 2,3 & 2,0 & 3,2 & 1,1 & 0,009 & 0,08 & 2,1 & 12 & 4,5 & 3,0 & 0,05 & 0,25 . & 0,06 & 4,6 \\
\hline Poá- F. Primavera & $10 / 07 / 75$ & 28 & 12 & 88 & 2,0 & 3,5 & 0,4 & 0,8 & 0,008 & 0,02 & 2,1 & 10 & 2,3 & 3,0 & 0,04 & 0 & 0,06 & 6,6 \\
\hline $\begin{array}{l}\text { Rochaguá- } \\
\text { F. Jaraguá }\end{array}$ & $24 / 10 / 75$ & 98 & 17 & 44 & 5,7 & 7,0 & 4,3 & 3,3 & 0,005 & 0 & 3,2 & 50 & 8,0 & 3,0 & 0,11 & 0 & 0,05 & 6,0 \\
\hline $\begin{array}{l}\text { Fontális - } \\
\text { F. São Joẫo }\end{array}$ & $19 / 11 / 75$ & 56 & 20 & 76. & 3,0 & 2,0 & 4,8 & 2,0 & 0,01 & 0 & 4,1 & 23 & 1,5 & 4,0 & 0,05 & 0,1 & 0,05 & 6,0 \\
\hline Petrópolis & $19 / 11 / 75$ & 80 & 17. & 28 & 6,0 & 6,7 & 3,5 & 2,0 & 0,03 & 0,04 & 3,2 & 25 & 6,0 & 12,0 & 0,04 & 0 & 0,03 & 9,0 \\
\hline
\end{tabular}


Tabela IV - Resultados das análises - Elementos traços (mg/l). Analisadas por M. Szikszay

\begin{tabular}{|c|c|c|c|c|c|c|c|c|c|c|}
\hline Nome da Fonte & I & $\mathrm{Br}$ & $\mathrm{F}$ & B & $\mathrm{Ni}$ & $\mathrm{Cu}$ & $\mathrm{Cr}$ (total) & $\mathrm{Zn}$ & $\mathrm{Pb}$ & Detergentes \\
\hline Jandira & $\mathbf{0}$ & 0,01 & 0,96 & 0,7 & 0 & 0,03 & 0,017 & 0,07 & 0,007 & 0,006 \\
\hline Pluma - F. dos Bandeirantes & 0,3 & 0,011 & 0,95 & 1,0 & 0,04 & 0,04 & 0,015 & 0,09 & 0,028 & 0,005 \\
\hline Embu - F. dos Jesuítas & & 0,01 & 0,95 & 0,2 & 0,04 & 0,05 & 0,012 & 0,14 & & 0,008 \\
\hline Pilar - F. da Encosta N. ${ }^{0} 1$ & 0,9 & 0,05 & 1,0 & 0,8 & 0,04 & 0,05 & 0,018 & 0,12 & 0,14 & 0,002 \\
\hline Pilar - F. da Montanha & 0,5 & 0,07 & 0,8 & 1,1 & 0,04 & 0,03 & 0,08 & 0,13 & 0,13 & 0,004 \\
\hline Pilar $-F_{t}$ Serrania & 0,31 & 0,02 & 0,95 & 0,9 & 0,03 & 0,03 & 0,018 & 0,09 & 0,14 & 0,002 \\
\hline Petra - F. Dotta & 0,4 & 0,02 & 0,8 & 1,5 & 0,03 & 0,02 & 0,013 & 0,019 & 0,12 & 0,003 \\
\hline Poá - F. Área & & $\mathbf{0}$ & 0,95 & 0,8 & 0,03 & 0,03 & 0,02 & 0,09 & & 0,005 \\
\hline Poá - F. Primavera & & 0 & 0,7 & 0,8 & 0,03 & 0,04 & 0,018 & 0,12 & & 0,005 \\
\hline Rochágua - F. Jaragua & 0,4 & 0,01 & 1,1 & 1,0 & 0,04 & 0,04 & 0,018 & 0,09 & 0,11 & 0,006 \\
\hline Fontális - F. São Joâo & 0,04 & 0,07 & $0,9^{\circ}$ & 0,7 & 0,04 & 0,03 & 0,018 & 0,08 & 0,08 & 0,004 \\
\hline Petrópolis & 0,1 & 0,015 & 0,92 & 0 & 0,05 & 0,03 & 0,018 & 0,12 & 0,028 & 0,001 \\
\hline
\end{tabular}

Os cloretos encontram-se em teores baixos que variam de 1 a $8 \mathrm{mg} / \mathrm{l}$, estando a média em torno de $3 \mathrm{mg} / \mathrm{l}$. Uma pequena anomalia nota-se na água de Rochágua e Petrópolis. No caso da água de Petrópolis, a concentração, um pouco mais elevada, deve-se à circulação das águas em rochas sedimentares argilosas fornecedoras de cloreto, e, também, à profundidade, uma vez que com a mesma determina-se um aumento de cloretos nas águas. $\mathrm{O}$ caso da água de Rochágua pode ser explicado pela presença de minerais contendo cloretos, tais como a apatita. Observa-se, também, que concentrações mais ou menos equivalentes ocorrem nas águas das Fontes Pilar (F. da Encosta N. ${ }^{\circ}$ 1), Petra e Poá (F. Áurea), todas provenientes de gnaisses. Concentrações baixas ( $2 \mathrm{mg} / \mathrm{l} \mathrm{ou} \mathrm{menos)} \mathrm{ocorrem}$ nas águas das outras fontes, todas provenientes de rochas graníticas, exceto a de Poá (F. Primavera) onde o terreno é muito alterado.

Os sulfatos encontram-se em teores baixos ou mesmo nulos, exceto na água de Petrópolis que circula em sedimentos, revelando, portanto, a influência do contexto hidrogeológico. Valores entre 3-5 mg/l encontram-se nas águas das Fontes Pilar (F. da Encosta N. ${ }^{\circ}$ 1), Poá, Rochágua e Fontális, todas circulando em gnaisses e xistos ou rochas semelhantes. Concentrações baixas (1-2 $\mathrm{mg} / 1$ ou mesmo nulas) encontram-se nas águas das demais fontes.

O fosfato encontra-se em teores em torno de $0,1 \mathrm{mg} / 1$ nas Fontes Pluma, Embu, Pilar (F. Serrania) e Rochágua. Nas águas de Rochágua e Embu tal fato pode ser devido à presença de apatita. Valores mais baixos $(0,05 \mathrm{mg} / \mathrm{l}$ ou nulo) encontram-se nas águas das fontes restantes. Não existe grande diferença de teores, porém, observarse que as águas dos granitos contêm um pouco mais do que aquelas provenientes das outras rochas. Ainda como fonte de fosfato na água, podé-se considerar os fertilizantes e detergentes.

Os teores em sódio e potássio são em geral baixos. Os valores menores de sódio são encontrados principalmente nas águas das Fontes Jandira, Pilar (F. da Encosta N. ${ }^{\circ}$ 1), Petra e Poá (F. Primavera). Sua origem se deve aos feldspatos sódicos das rochas graníticas e gnáissicas. Concentrações um pouco mais elevadas foram encontradas nas águas das fontes restantes. O potássio é encontrado em teores baixos nas águas das fontes de Pluma, Embu, Pilar (F. da Montanha e F. Serrania), Petra e Poá, onde o contexto geológico é 
granítico. Nas fontes restantes, com tipos de rochas diversas, as concentrações são um pouco mais elevadas. Em geral, o potássio é encontrado nas águas em concentrações baixas, devido à adsorção desse elemento pelos minerais de argila. Nas águas de Rochágua os teores mais altos estão relacionados com a presença de feldspatos potássicos.

Os teores em alumínio variam de 0,001-0,01 mg/1 nas amostras estudadas. Concentrações de 0,01 mg/l encontram-se nas águas das Fontes de Jandira, Pluma, Embu, Pilar (F. da Montanha e F. Serrania) e Fontális ou seja provenientes dos granitos. Os valores mais baixos encontram-se nas águas das fontes restantes, salvo a da F. Petrópolis, onde concentrações relativamente altas foram encontradas, devido aos sedimentos onde a água circula.

Não existem grandes variações nos teores de ferro. Os valores um pouco mais elevados nas águas da Fonte Pilar (F. da Encosta N. ${ }^{\circ}$ 1) podem estar relacionados ao fato da amostragem ter sido feita no cano de ferro de descarga. Não existe ferro nas águas das Fontes Pilar (F. da Montanha), Rochágua e Fontális.

A sílica em solução encontra-se em concentrações baixas $(1,1$ a $4,1 \mathrm{mg} / \mathrm{l})$, o que era de se esperar, tendo em vista os valores de $\mathrm{pH}$.

A amônia não foi detectada nas águas de Embu, Pilar, Poá (F. Primavera), Rochágua e Petrópolis. Teores baixos são encontrados nas águas das Fontes de Jandira e um pouco mais nas restantes.

Os nitritos são baixos nas águas de todas as fontes; um teor pouco mais elevado encontra-se nas de Pluma e Pilar (F. da Montanha).

Os nitratos, sendo a fase final do ciclo de $\mathrm{NH}_{4}-\mathrm{NO}_{2}-\mathrm{NO}_{3}$, encontram-se em concentrações baixas. Nota-se, porém, um pequeno aumento com a profundidade das captações. O nitrato concentra-se à medida que se infiltra e, assim, os teores mais elevados são encontrados nas captações mais profundas como o poço de Petrópolis.

$\mathrm{O}$ iodo e o iodeto encontram-se em teores mais ou menos iguais nas águas de todas as fontes. Os valores são um pouco mais elevados nas águas da Fonte Pilar (F. da Encosta $\mathrm{N} .^{\circ}$ 1). Os teores variam de $0-0.9 \mathrm{mg} / \mathrm{l}$, o que não é suficiente para definição de água mimineral. Sua origem é atribuída à decomposição da matéria orgânica (vegetação).

Os teores em brometo nas nossas amostras variam de 0,01-0,07 mg/l. Não se verifica grande diferença nas concentrações; nas Fontes de Pilar (F. da Encosta N. ${ }^{\circ}$ e F. da Montanha) e Fontális são mais elevadas, sendo essas águas provenientes de granitos com pegmatitos nas proximidades.

Os teores em fluoreto são mais ou menos iguais nas águas de todas as fontes $(0,9 \mathrm{mg} / \mathrm{l})$. $O$ fluoreto é freqüentemente encontrado em rochas ígneas e metamórficas como componente de anfibólios, tais como hornblenda, micas e de outros minerais, onde substitui parte do grupo $\mathrm{OH}^{-}$na estrutura mineral (Rankama e Sahama, 1950). Rochas sedimentares também contêm fluoreto como constituintes menores.

O boro é um constituinte menor nas águas. Sua origem pode ser atribuída aos minerais que contêm boro, como a turmalina que, geralmente, é um constituinte de rochas graníticas e pegmatíticas. Encontra-se, ainda, em algumas rochas metamórficas. Nas nossas amostras o boro encontra-se com teores variando de $0,2-1,5 \mathrm{mg} / \mathrm{l}$. Valores mais elevados são chucontridos nas águas provenientes de granitos e/ou de pegmatitos [Fontes Pluma, Pilar (F. da Montanha e F. Serrania), Petra e Rochágua], onde foi constatada a presença de turmalina.

Tanto o cobre como o níquel são elementos-traços comuns nas águas naturais. Suas propriedades geoquímicas são semelhantes e observa-se que se encontram em teores semeIhantes nas amostras (Cu 0,02-0,05 mg/l e Ni 0,03-0,05 mg/l). 
O crômio está presente em teores baixos nas rochas ígneas. Todas as amostras de água apresentam valores baixos $(0,012-0,08 \mathrm{mg} / \mathrm{l})$. Os valores mais elevados pertencem às fontes de Pilar (F. da Montanha) e Poá (F. Áurea).

$\mathrm{O}$ zinco pode substituir o magnésio e o ferro em alguns minerais e está presente nas rochas graníticas, nos minerais biotita e anfibólio. Entra em solução durante a decomposição e alteração química das rochas. Está presente também nas plantas e animais. Nas amostras coletadas encontra-se em teores baixos $(0,019-0,14 \mathrm{mg} / 1)$. Os valores mais altos pertencem às águas de Embu, Pilar (F. da Encosta N. ${ }^{\circ}$ 1), Poá (F. Primavera) e Petrópolis.

O chumbo pode ocorrer nos feldspatos potássicos onde substitui o potássio. Encontra-se nas nossas amostras em teores baixos $(0,007-0,14 \mathrm{mg} / \mathrm{l})$. Os teores mais elevados pertencem às águas de Pilar, Petra e Rochágua e os mais baixos às fontes Jandira, Pluma, Fontális e Petrópolis.

Detergentes presentes nas águas amostradas encontram-se em teores variando de $0,001-0,008 \mathrm{mg} / \mathrm{l}$. Sua origem mais provável são os produtos usados na limpeza das captações.

As análises bacteriológicas realizadas evidenciaram a presença de bactérias coliformes em apenas uma fonte.

Influência da litologia na composição química das águas TROCA DE BASES(i.e.b.) Para estudar o comportamento dos elementos e compostos éncontrados nas águas das fontes e relacioná-los à litologia dos arredores das fontes, como também à dinâmica da água em contato com o terreno, utiliza-se inicialmente o cálculo de troca de bases, segundo a fórmula a seguir.

$$
i . e . b .=\frac{r \mathrm{Cl}-r(\mathrm{Na}+\mathrm{K})}{r \mathrm{Cl}}
$$

onde $r$ (reacting value), é dado em miliequivalentes por litro. Os valores das trocas de bases encontram-se na Tab. V.

Observa-se que a maioria das águas das fontes tem i.e.b. negativo, o que era de se esperar. Segundo Schoeller (1962) águas provenientes de rochas cristalinas têm i.e.b. negativo e os alcalinos da água são fornecidos pelo terreno. As águas das Fontes Jandira, Pluma, Embu, Pilar (F. da Montanha e F. Serrania) e Fontális (com i.e.b. igual a -1,2, $-2,4,-7,5,-3,7,-1,0 \mathrm{e}-5,2$ respectivamente) são as que apresentam i.e.b. negativo mais alto, indicando circulação rápida e são águas que circulam em fissuras de granitos. $O$ valor de i.e.b. zero ou próximo a zero significa equilíbrio dos compostos da água com os das rochas e, indica que a água permanece durante um certo tempo em contato com o terreno, sendo, portanto, de circulação mais lenta [Petra, Poá (F. Áurea), Rochágua, Petrópolis e Pilar (F. da Encosta N. ${ }^{\circ}$ ), com i.e.b. igual a $0,-0,25,-0,18,-0,43$ e $-0,11$, respectivamente].

O i.e.b. positivo é encontrado em águas onde os alcalinos são fornecidos pela água e trocados pelos alcalino-terrosos do terreno. São as águas da Fonte Poá (Primavera) que circulam em gnaisses e micaxistos. Gomo todos os valores de i.e.b. estão também próximos a zero, pode-se supor que essas águas estivessem em contato com o terreno já há certo tempo, que a circulação seja mais lenta e que o i.e.b., originalmente negativo, tenha sido mudado para positivo.

RELAÇOEES CARAGTERÍSTICAS Para um estudo melhor de comparação entre as várias águas, as relações características são mais significativas. Assim, verificam-se as relações características seguintes, cujos valores se encontram na Tab. V. 
Tabela V - Valores dos índices de troca de bases e relações características das águas das fontes estudadas

\begin{tabular}{lcc}
\hline \multicolumn{1}{c}{ Fonte } & i.e.b. & $r \mathrm{Mg} / \mathrm{Ca}$ \\
\hline Jandira & $-1,20$ & 1,1 \\
\hline Pluma - Fonte dos Bandeirantes & $-2,4$ & 2,1 \\
\hline Embu - Fonte dos Jesuítas & $-7,5$ & 0,8 \\
\hline Pilar - Fonte da Encosta N. ${ }^{\circ} 1$ & $-0,11$ & 2,2 \\
\hline Pilar - Fonte da Montanha & $-3,7$ & 2,3 \\
\hline Pilar - Fonte Serrania & $-1,0$ & 5,0 \\
\hline Petra - Fonte Dotta & 0 & 16,6 \\
\hline Poá - Fonte Aurea & $-0,25$ & 1,4 \\
\hline Poá - Fonte Primavera & $+0,5$ & 2,9 \\
\hline Rochágua - Fonte Jaraguá & $-0,18$ & 2,0 \\
\hline Fontális - Fonte São João & $-5,2$ & 1,0 \\
\hline Petrópolis & $-0,43$ & 1,8 \\
\hline
\end{tabular}

$r \mathrm{Mg} / r \mathrm{Ca}$ - Tanto o cálcio como o magnésio estão sempre presentes nas águas naturais. Geralmente o cálcio é encontrado mais abundantemente do que o magnésio. Quando a relação $r \mathrm{Mg} / r \mathrm{Ca}$ encontra-se entre 0,8-1,0 (Hem, 1959), a água circula em rochas onde a quantidade de cálcio e magnésio é fornecida pela rocha em proporções mais ou menos equivalentes. Isso acontece nas águas das fontes de Embu e Fontális, ambas circulando em granitos, com circulação rápida indicada pelo i.e.b. negativo, bastante afastado de zero. Quando a relação $r \mathrm{Mg} / r \mathrm{Ca}>1$ indica que o magnésio foi fornecido pela troca de bases. Todas as águas restantes apresentam esse valor, permitindo admitir-se que o magnésio encontrado na água foi adquirindo sua concentração pela troca de bases, ou seja, o terreno forneceu o magnésio para a água. Como fontes de magnésio citaremos alguns minerais, tais como biotita, diopsídio, hornblenda, granada, os plagioclásios, todos presentes de maneira variável nas rochas onde circulam as águas amostradas. Em geral, observa-se que a razão característica não mostra grande variação, salvo da água da Fonte Petra, onde a fonte surge na fissura de xistos com grafita e com muita biotita, portanto muito magnésio e da fonte de Embu onde o teor mais elevado em cálcio provém da dissolução da calcita identificada na rocha.

Para uma visualização comparativa da distribuição das águas das fontes, os dados foram colocados no diagrama de Piper (Fig. 2). Esse diagrama permitiu estabelecer sua separação em dois grupos. $O$ primeiro grupo que inclui as águas das fontes $1,2,3,5,6$, 10 e 11 e o segundo grupo as águas das fontes $4,7,8,9$ e 12. As fontes do grupo I correspondem às rochas graníticas e migmatíticas e do grupo II pertencem aos gnaisses, micaxistos, xistos e rochas sedimentares. No grupo II destaca-se a fonte 4 que situa no contato gnaisse-granito e que por suas características relativas aos elementos traços, quanto ao brometo, chumbo e zinco, assemelha-se às rochas graníticas e em boro às rochas gnáissicas. A fonte 9, ligeiramente diferente, tem sua emergência nos xistos muito alterados. Essa fonte reflete, através de seus elementos-traços (fluoreto e zinco), uma contribuição pro- 


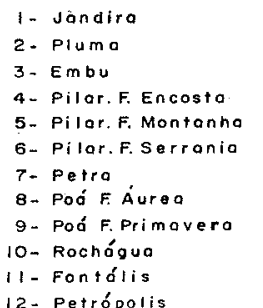

12. Petrópolis

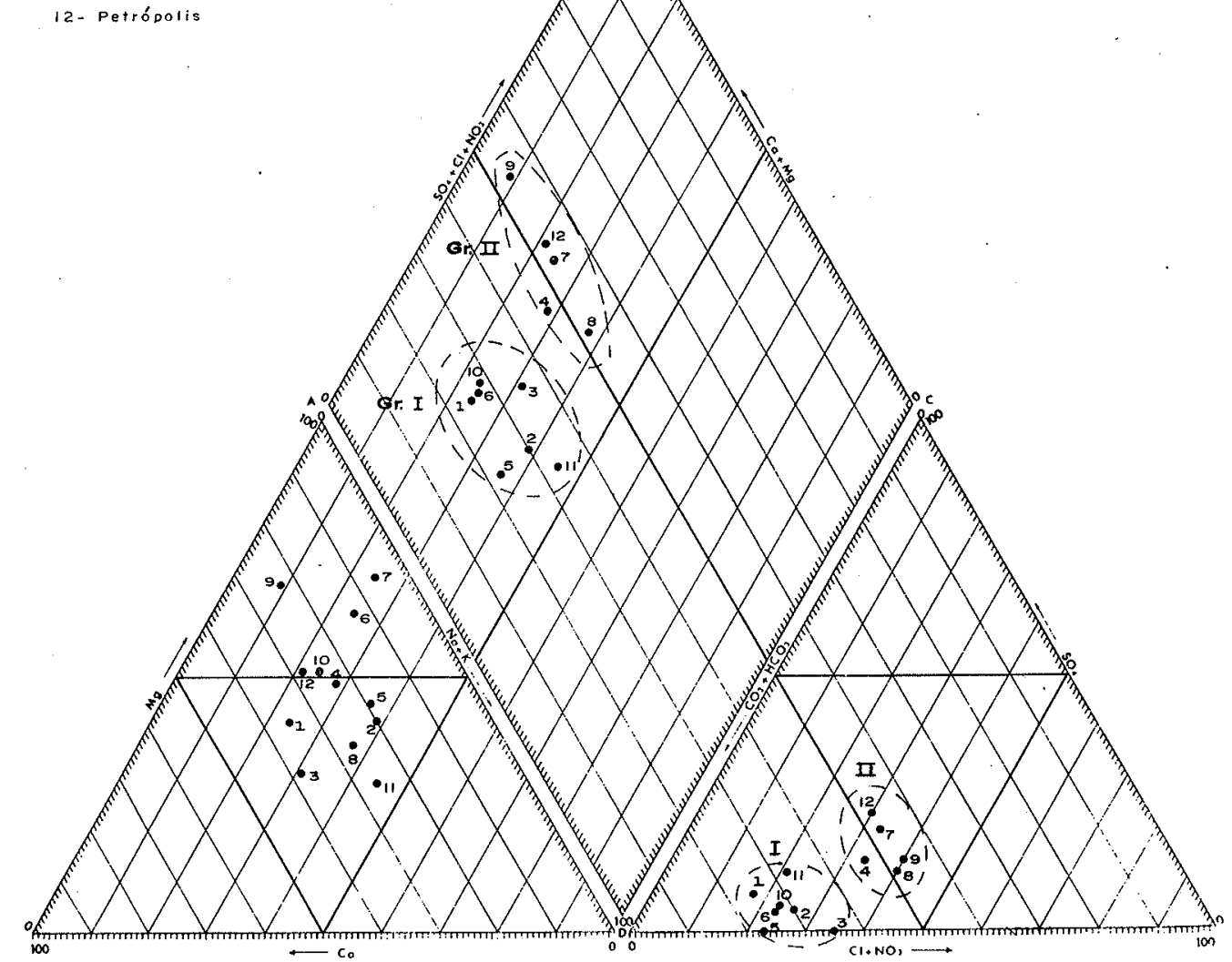

Figura 2 - Principais grupos de águas segundo o diagrama de Piper

veniente das rochas alteradas. A água de Petrópolis distingue-se do resto pela temperatura mais elevada, condutividade maior, $\mathrm{CO}_{2}$ mais baixo, cloreto, sulfato e alumínio mais elevados, características que refletem sua origem profunda e influência dos terrenos sedimentares.

As águas das Fontes Jandira, Pilar, Petra, Poá (F. Primavera), Rochágua e Petrópolis são bicarbonatadas magnesianas, as de Embu bicarbonatada calco-sódica, as de Pluma e Fontális bicarbonatadas sódicas e as da Poá (F. Áurea) bicarbonatada sódio-magnesiana. As águas podem ser classificadas, quanto aos ânions, como predominantemente bicarbonatadas e quanto aos cátions, como predominantemente magnesianas.

CONCLUSÃO A interpretação dos resultados permitiu relacionar as águas das fontes estudadas com a litologia representada, predominantemente, de um lado, por granitos e migmatitos, e de outro lado, por gnaisses e micaxistos. As águas das fontes dos arredores 
da bacia de São Paulo, caracterizam-se por uma condutividade baixa, devida a uma mineralização fraca, que é consequiência de uma circulação rápida nas fissuras. Isso é confirmado pelo índice de troca de bases negativo. $\mathrm{O}$ pH ácido e a predominância dos bicarbonatos como ânions são representativos de águas de rochas cristalinas sob um clima tropical ou subtropical. Nota-se igualmente nessas águas a presença de iodeto, amônia, nitrito e nitrato proveniente da decomposição da matéria orgânica abundante sob esses climas. O enriquecimento em flúor é devido à apatita, e o boro sempre está associado aos filões de pegmatitos com turmalina. Na sua maioria, as águas são bicarbonatadas magnesianas e secundariamente cálcicas ou sódicas. Todas as fontes podem ser classificadas como minerais somente em função da radioatividade na emergência. Segundo suas composições químicas colocam-se na categoria de águas de mesa.

\section{BIBLIOGRAFIA}

CASTANY, G. - 1967 - Traité pratique des eaux souterraines, Dunod, Paris

COUTINHO, J. M. V. - 1972 - Petrologia do pré-Cambriano de São Paulo e Arredores. Bol. IG. n. $^{\circ} 3$, USP

C.P.R.M. - 1974 - Mapa geológico de São Paulo

HEM, J. D. - 1959 - Study and Interpretation of the Chemical Characteristics of Natural Water. Geol. Survey Water Supply Paper 1473, United States Govern. Printing Office, Washington

LONGO, W. O. - 1967 - Aguas radioativas no Estado de São Paulo. Revista do IGG, n. ${ }^{\circ}$ 19, São Paulo

RANKAMA, K. and SAHAMA, TH. G. - 1950 - Geochemistry. The University of Chicago Press

SCHOELLER, H. - 1962 - Les eaux souterraines. Masson \& Gie Editeurs, Paris

SOUZA LOPES, R. - 1956 - Águas Minerais do Brasil. DNPM, Rio de Janeiro 